\title{
Recent advances in flood forecasting and flood risk assessment
}

\author{
Gabriel Arduino ${ }^{1}$, Paolo Reggiani ${ }^{2}$ and Ezio Todini ${ }^{3}$ \\ ${ }^{1}$ World Meteorological Organization, Geneva, Switzerland \\ ${ }^{2}$ WL | Delft Hydraulics, The Netherlands \\ ${ }^{3}$ University of Bologna, Bologna, Italy \\ Email for corresponding author: paolo.reggiani@wldelft.nl
}

\section{Introduction}

Recent large floods, such as those in the Meuse and Rhine basins in 1995, over large areas of the UK in 1998 and 2000 and in the Elbe basin in summer 2002, have led to increased interest in research and development of flood forecasting systems. Some of these periods, such as the autumn and winter of 2000/2001 in England and Wales, have been the wettest on record (Marsh, 2001). This has led to speculation that such extremes are attributable in some measure to anthropogenic global warming and represent the beginning of a period of higher flood frequency. Whilst current trends in extreme event statistics will be difficult to discern, conclusively, until some time in the future, Milly et al. (2002) have shown a substantial increase in the frequency of high floods in the 20th century for basins greater than $2 \times 10^{5} \mathrm{~km}^{2}$. There is also increasing evidence (Milly et al., 2002; Palmer and Räisänen, 2002) that anthropogenic forcing of climate change may lead to an increased probability of extreme precipitation and, hence, of flooding. For example, Palmer and Räisänen (2002) have calculated likely probabilities of extreme precipitation using multi-model ensembles of Global Circulation Model output for reference baseline and typical enhanced $\mathrm{CO}_{2}$ scenarios. These suggest that the probability of total boreal winter precipitation exceeding two standard deviations above normal will increase by a factor of five over parts of northern Europe over the next 100 years.

In view of these prospective developments, there is major emphasis on the improvement of operational flood forecasting systems in Europe, with significant European Community spending on research and development on prototype forecasting systems and flood risk management projects. This Special Issue synthesises the most relevant scientific and technological results presented at the
International Conference on Flood Forecasting in Europe held in Rotterdam from 3-5 March 2003. During that meeting 150 scientists, forecasters and stakeholders from four continents assembled to present their work and current operational best practice and to discuss future directions of scientific and technological efforts in flood prediction and prevention. The papers presented at the conference fall into seven themes, as follows.

\section{Precipitation forecasts}

Advances in flood forecasting beyond the present state of the art are to be achieved, amongst others, on the basis of extending forecast lead time and corresponding skill several days into the future. This is achievable following recent advances in numerical weather predictions at various timeranges and spatial resolutions. The weather forecasting products relevant for flood forecasting purposes in the category of short-range (up to 72 hours ahead) and mediumrange forecasts (up to 10 days ahead) are either deterministic or, increasingly, are based on ensemble prediction techniques. These entail a random perturbation of the initial and boundary conditions of the weather model, as it is impossible to determine the state of the atmosphere exhaustively at a particular point in time. The probabilistic forecasts are supposed to account for the uncertainties resulting from the chaotic development of the non-linear weather system while ensemble realisations capture the stochastic properties of the forecast precipitation and temperature fields.

The precipitation-forecast related contributions presented in this Special Issue (Bongioannini et al.,2005; Sattler and Feddersen, 2005) investigate the orographic effects on local weather systems, with the aim of reproducing cumulative 
precipitation recorded during historical events. It has been shown that convective precipitation events are generally under-predicted, as the vertical acceleration and subsequent condensation of moist air masses attributable to steep orographies are not accounted for adequately. Progress in this area is achieved by employing models with high spatial resolution, ranging from 2 to $200 \mathrm{~km}$, which are able to capture convection cells and physical effects at the spatial scale of interest. An attempt is also made to produce forecasts with a high-resolution local area model in deterministic mode and to provide mini ensembles with the DMIHIRLAM hydrostatic model (Undén et al., 2002). These have been compared with results from the ECMWF Ensemble Prediction System (Mullen and Buizza, 2001); the ability of high-resolution weather models to reproduce, successfully, the effects of convective precipitation constitutes a significant step towards improved skill in capturing orographic effects in forecast mode.

\section{Coupling precipitation forecasts and hydrological models}

Flood forecasting systems combine hydrological models for the land-phase with hydraulic models to simulate flood propagation throughout the drainage network. These tools are driven by environmental forcing factors such as meteorological variables like precipitation, temperature and evaporation, updated by data from additional information sources such as radar-borne measurements and groundbased gauging networks. The interlinked chain of hydrological and river routing models is used, subsequently, to predict not only water levels and discharge at critical locations along the river system but also distributed fields of water depth and flow velocity, given only adequate digital terrain models (DTMs). This type of model chain is the core of flood forecasting systems and approaches described in this Special Issue. Some contributions deal explicitly with the effects of coupling the land phase models with the output of numerical weather products, investigating the effects of horizontal resolution of the weather models on the hydrological response of the basins. The hydrological models used in the studies are either purely data-driven or conceptual tools such as the neural network model by Shresta et al. (2005), the HEC model applied to the Savinja and Koritnica basins in the Republic of Slovenia (Kobold and Sušelj, 2005) or process-oriented, spatially-distributed models such as the TOPKAPI model (Bartholmes and Todini, 2005; Liu and Todini, 2005) applied to the upstream part of the Po basin and the Upper Xixian catchment in the Huaihe basin. The distributed process-based rasterised model LISFLOOD (De Roo et al., 2000) is employed in the application to the Meuse and Odra basins by Gouweleeuw et al. (2005) and Pappenberger et al. (2005).

Driving the hydrological models with numerical weather hindcasts and comparing the computed discharges with corresponding historical flood data, shows the structural underprediction of the cumulative precipitation, especially for situations in which pronounced orography plays a significant role. All papers on the subject agree on the need for improvements in the forecasting skill of numerical weather prediction, especially by increasing the horizontal resolution of the models and by focusing on an adequate representation of the physics inherent in orograpahic effects, if the numerical predictions are to become operationally employable routinely for flood forecasting purposes.

\section{Data-driven hydrological models}

A particular role in flood forecasting can be attributed to the approaches used for selecting adequate rainfall-runoff models for the hydrological response of the land phase. It is generally anything but straightforward to generalise a typology for the models to be used in real-time flood forecasting, because the choice of the models is heavily dependent on catchment size, the characteristics of the runoff phenomena and the envisaged forecasting lead time. It is often argued that there is significant difference in dealing with real-time flood forecasting in small, flashy catchments compared to large river basins such as the Po, the Rhine or the Danube.

Moreover, there are two principal lines of thought in the development of rainfall-runoff models. The first, originated by the continuous flow of observations collected round the clock, puts a higher emphasis on measurements and data, while it proposes to develop very simple statistical or parametric models, whose parameters may be estimated and updated continuously through calibration. The model acts either as a black box, whose internal processes are tuned via parameter sets, or represents some hydrological processes in a translated, conceptual fashion. The second approach, while still recognising the need for data, believes that the highly non-linear behaviour of the rainfall-runoff process may not be fully represented in the limited set of data used for the calibration (the training set) and must be introduced to the models as a priori knowledge, to reduce uncertainty and improve the reproduction of physical phenomena beyond the time range for which observations are available (Kitanidis and Bras, 1980a, b; Brath and Rosso, 1993).

As a result of these two lines of thought, diverse models have been developed for flood forecasting purposes. These range from extremely simplified tools, possibly recalibrated 
in real-time, to systems based on complex rainfall-runoff models, which take soil moisture and its continuous lateral redistribution due to the interplay of gravity and topography explicitly into account. Soil moisture is continuously updated on the basis of the water balance equation stated for a spatial entity or control volume.

The principal limit of the simpler black-box or simple conceptual models lies in the fact that they are not able to capture adequately the non-linear processes leading to the saturation of the subsurface and the subsequent generation of surface runoff. Moreover, they need to be recalibrated constantly. This may turn out to be a data-intensive and onerous procedure, especially when the catchments are subject to substantial changes in land use and land management practices, which may have non-negligible impacts on their hydrological responses. Process-based models, accounting for spatially-distributed information, are more likely to represent the cause-effect relationships leading to changing runoff behaviour. The present Special Issue presents versions of both types of model. A typical example of data-driven models is given in the paper by Shresta et al. (2005), in which a neural network model is trained, with the aid of a one-dimensional hydrodynamic numerical model, on a data set for the river Neckar in Germany. This case study shows the applicability of the approach for different activation functions of the neural network and explores the range of validity of the network chosen for the simulations. The paper by Goswami et al. (2005) compares eight rainfall runoff models on the Brosna River in Ireland. The selected models are either exclusively data-driven, ranging from linear and non-linear autoregression approaches to neural network models, or use soil moisture accounting to reproduce mechanisms for flood generation.

\section{Process-based hydrological models}

Process-based rainfall-runoff models have the principal advantage that they represent, explicitly, runoff-generation mechanisms in terms of the underlying physics such as infiltration, exfiltration, the lateral distribution of soil moisture and the localised saturation of the shallow subsurface in a spatially-distributed fashion. This type of process representation adds to the complexity of the model but precludes continuous re-calibration of the model for changing environmental conditions. While these models were generally over-parameterised, several attempts in the literature have reduced the number of parameters necessary by integrating the governing equations over suitable control volumes or characteristic spatial entities. The TOPKAPI model by Liu and Todini, (2005) represents such a comprehensive process-based model, which offers wideranging applicability for flood forecasting applications, and has a clear potential for the Prediction of Ungauged Basins (PUB). The physical processes are integrated from the pointscale to the scale of pixels of up to $1 \mathrm{~km}^{2}$. Alternatively, the LISFLOOD model (De Roo et al., 2000; Gouweleeuw et al., 2005) and its extension module for inundation modelling LISFLOOD-FP used by Pappenberger et al., (2005), is a rasterised version of a process-based model, the preferred use of which is for flood forecasting in large river basins. LISFLOOD may also be suitable for hydrological simulations at the continental-scale, as it uses topographic and land-use maps with a spatial resolutions up to $5 \mathrm{~km}^{2}$. In this spirit it has been adopted as the hydrological response model in the European Flood Forecasting System (EFFS).

\section{Assessing predictive uncertainty}

To be of value, a flood warning must be associated with an objective measure of uncertainty. Uncertainty generally increases with the lead-time needed to implement flood protection measures. Quantifying uncertainty is increasingly relevant as political pressure mounts to provide medium to long-term flood forecasts from numerical weather predictions. The sources of uncertainty and their propagation throughout the flood forecasting process are manifold, principally in the estimate of precipitation, followed by the uncertainty attributable to the internal states of the hydrological and hydraulic models, the initial conditions and relevant process parameterisations. These uncertainties depend, significantly, on the particular type of model. The predictive uncertainty must be quantified adequately, so that methods for a systematic reduction in uncertainty by means of observations can be employed in a probabilistic analysis framework (such as for example the Bayesian framework proposed by Krzystofowicz, 1999). Two contributions in this Special Issue address the predictive uncertainty from different perspectives. The paper by Hunter et al. (2005) applies the Generalised Likelihood Uncertainty Estimation (GLUE) procedure (Beven and Binley, 1992) in exploring the value of various observations in constraining predictions of inundated surfaces with the LISFLOOD-FP model. The principal source of uncertainty in the inundation modelling is attributable to the friction parameters of the bed in simulating the 2-D diffusion of the flood wave over lowlying areas. The paper by Pappenberger et al. (2005) examines the cascading of uncertainty from an ensemble weather prediction system through the rainfall-runoff model LISFLOOD and the inundation model LISFLOOD-FP by means of the GLUE procedure. It is concluded that the dissemination of the concepts underlying uncertainty to the 
decision-makers and the related adaptation in decisionmaking culture remains a major challenge to be addressed by collaboration between the scientists and end-users of the forecasts. The explicit consideration of a forecast in probabilistic terms allows the taking of the most effective decisions in the face of uncertainty (e.g. Raiffa and Schlaifer, 1961; Todini, 1999).

\section{Assessing flood risk}

Another important aspect in flood forecasting is the estimation of the risk of future extreme discharges that may expose societies to dangerous situations. Risk assessments may be based on indicators of how prone a given basin is to flooding for a given forecast of precipitation and antecedent soil moisture conditions. Hlavcovà et al. (2005) use the soil moisture in the basin as a criterion in estimating flood risk. In their study, they force a flash-flood basin, the $1750 \mathrm{~km}^{2}$ Hron catchment in the Slovak Republic, with synthetic precipitation for different antecedent soil moisture conditions; from these, synthetic flood events and related critical return periods are estimated. This technique is well suited to off-line estimations of extreme discharges and related flood risk.

The contribution by Sanders et al. (2005) illustrates the relevance of accurate terrain surveys for inundation risk in the insurance industry. The paper looks at the insurance implications of recent flood events in Europe and the issues surrounding insurance of potential future events. In particular, it assesses the flood risk information needed by insurers and considers how best these can be met. The data requirements of national and regional flood models are addressed in the context of the accuracy of available data on property location, given that terrain information is generally one of the weaker components of sophisticated flood models. Different sources of digital terrain models (DTM) are examined and discussed in relation to the vertical and horizontal accuracy, the speed of acquisition, the costs and the comprehensiveness of the data.

\section{Operational flood forecasting}

At present, the performance of many flood forecasting systems in an operational context is sub-optimal and often below expectation. The information they are designed to provide fails to reach much of the target audience, the members of which remain unsatisfied with the information they expect to receive. The source of this poor performance is generally the weak connection in the chain linking the flood forecasting process with those charged with responding to crises and especially with the public exposed to the risks. Without strengthening the performance of the dissemination component, the entire flood forecasting process remains significantly weakened. As repeatedly emphasised by several authors (e.g. Penning-Rowsell and Fordham, 1994; Handmer and Penning-Rowsell, 1990; Parker and Fordham, 1996), a flood warning system can be conceptualised as the combination of a flood forecasting sub-system (the technological-scientific component) and a flood warning dissemination sub-system (the social component), mutually linked through a suitable feedback mechanism. The messages generated by the technical part of the system must be converted promptly into simple and understandable messages that are easily and univocally interpretable by the decision-makers and the public.

In the specific context of operational systems, two contributions are presented in this Special Issue. Rabuffetti and Barbero (2005) illustrate the development and the implementation of a real-time Flood Forecasting System for the hydro-meteorological operational alert procedure for the Region of Piedmont, Italy. The system focuses on the upper Po basin, a river system some $3000 \mathrm{~km}$ long with a drainage basin surface of $37000 \mathrm{~km}^{2}$. A case study of an event in October 2000, during which the north-west of Italy experienced one of the largest floods on record, is analysed. The results show how predictive uncertainty is an essential feature of the forecast and greatly affects its quality. A system expressed in terms of coded risk levels is proposed as an effective tool in translating the predictive uncertainty into alert levels that can be understood and acted upon by the decision-makers.

\section{Epilogue}

The broad spectrum of thematic areas and contributions presented in this Special Issue demonstrates the development of flood forecasting from a purely hydraulic and hydrological discipline into a cross-cutting multidisciplinary research field, ranging from meteorology via statistics, hydrology and hydraulics all the way to communication science. Hence, this field must be studied and understood from disparate angles and professional view points.

The conference contributed significantly to bringing the involved communities together and to fostering a muchneeded exchange of experience and innovation; it also brought into the open numerous questions and needs of the various professionals

The present HESS Special Issue was organised by the Chief Editor and the two Guest Editors as part of their contribution to the EFFS project and related communication und dissemination activities. The Editors express their gratitude towards all those scientists and professionals who 
have provided valuable contributions and have given the necessary support that has led to the publication of this Special Issue.

\section{References}

Bartholmes, J. and Todini, E., 2005. Coupling meteorological and hydrological models for flood forecasting. Hydrol. Earth Syst. Sci., 9, 55-68.

Beven, K.J and Binley, A.M., 1992. The future of distributed models: model calibration and uncertainty prediction. Hydrol. Process., 6, 279-298.

Bongioannini-Cerlini, P., Emanuel, K.A. and Todini, E., 2005. Orographic effects on convective precipitation and space-time rainfall variability. Preliminary results. Hydrol. Earth Syst. Sci., 9, 7-21.

Brath, A. and Rosso, R., 1993. Adaptive calibration of a conceptual model for flash flood forecasting. Water Resour. Res., 29, 25612572.

De Roo, A.P.J., Wesseling, C.G. and Van Deursen, W.P.A., 2000. Physically-based river basin modelling within a GIS: The LISFLOOD model. Hydrol. Process., 14, 1981-1992.

Goswami, M., O'Connor, K.M., Bhattarai, K.P. and Shamseldin, A.Y., 2005. Real-time river flow forecasting for the Brosna Catchment in Ireland using eight updating models. Hydrol. Earth Syst. Sci., 9, 116-133.

Gouweleeuw, B.T., Thielen, J., Franchello, G., De Roo, A.P.J. and R. Buizza, R., 2005. Flood forecasting using probabilistic weather prediction. Hydrol. Earth Syst. Sci., 9, 87-102.

Handmaer, J.W. and Penning-Rowsell, E.C.(Eds.), 1990. Hazard and communication of risk. Gower Technical Press, Adlershot, UK.

Hlavcovà, K., Kohnova, S., Kubes, R., Szolgay, J. and Zvolensky, M., 2005. Estimation of future flood risk for flood warning systems. Hydrol. Earth Syst. Sci., 9, 153-170.

Hunter, N.M., Bates, P.D. and Horritt, M.S., 2005. Utility of different data types for calibrating flood inundation models within a GLUE framework. Hydrol. Earth Syst. Sci., 9, 134152.

Kitanidis, P.K. and Bras, R.L., 1980a. Real-time forecasting with a conceptual hydrological model: 1: Analysis of uncertainty. Water Resour. Res., 126, 1025-1033.

Kitanidis, P.K. and Bras, R.L., 1980b. Real-time forecasting with a conceptual hydrological model: 2: Application of results. Water Resour. Res., 126, 1034-1044.

Krzystofowicz, R., 1999. Bayesian theory of probabilistic forecasting via deterministic hydrological model. Water Resour. Res., 35, 2739-2750.

Liu, Z. and Todini, E., 2005. Flood forecasting using a fully distributed model: application to the upper Xixian catchment. Hydrol. Earth Syst. Sci., 9, 69-86.
Marsh, T. J., 2001. The 2000/01 floods in the UK: a brief overview. Weather, 56, 343-345.

Milly, P.C.D., Wetherald, R.T., Dunne, K.A. and Delworth, T.L., 2002. Increasing risk of great floods in a changing climate. Nature, 415, 514-517.

Mullen, S. and Buizza, R., 2001, Quantitative precipitation forecasts over the United States by the ECMWF Ensemble Prediction System. Mon. Weather Rev., 129, 638-663.

Kobold, M. and K. Sušelj., 2005. Precipitation forecasts and their uncertainty as input into hydrological models. Hydrol. Earth Syst. Sci., 9, 44-54.

Palmer, T.N. and Räisänen, J., 2002. Quantifying the risk of extreme seasonal precipitation events in changing climate. Nature, 415, 512-514.

Parker, D.J. and Fordham, M., 1996. An evaluation of flood forecasting, warning and response systems in the European Union. Water Resour. Manage., 10, 279-302.

Pappenberger F., Beven K.J., Hunter N., Bates, P., Gouweleeuw, B.T., Thielen, J. and De Roo, A.P.J., 2005. Cascading model uncertainty from medium range weather forecasts (10 days) through a rainfall-runoff model to flood inundation predictions within the European Flood Forecasting System (EFFS). Hydrol. Earth Syst. Sci., 9, 103-115.

Penning-Rowsell, E.C. and Fordham, M. (Eds.), 1994. Floods across Europe: hazard assessment, modelling and management. Middlesex University Press, London, UK.

Rabuffetti, D. and Barbero, S., 2005. Operational MeteoHydrological Warning and Real Time Flood Forecasting. The Piemonte Region Case Study. Hydrol. Earth Syst. Sci., 9, 179188.

Raiffa, H. and Schlaifer, R., 1961. Applied statistical decision theory. MIT Press, Cambridge, Massachusetts, USA.

Sanders, R., Shaw, F., MacKay, H., Galy, H. and Peterk, O., 2005. National flood modelling for insurance purposes: using IFSAR for flood risk estimation in Europe. Hydrol. Earth Syst. Sci., 9, 171-178.

Sattler, K. and Feddersen, H., 2005. Limited-area short-range ensemble predictions targeted for heavy rain in Europe. Hydrol. Earth Syst. Sci., 9, 22-34.

Shrestha, R., Theobald, S. and Nestmann, F., 2005. Simulation of flood flow in a river system using artificial neural networks. Hydrol. Earth Syst. Sci., 9, 35-43.

Todini, E., 1999. Using phase-space modelling for inferring forecasting uncertianty in non-linear stochastic decision schemes. J. Hydroinformatics, 01.2, 75-82.

Undén, P., Rontu, L., Järvinen, H., Lynch, P., Calvo, J., Cats, G., Cuxart, J., Ereola, K., Fortelius, C., Garçia-Moya, J.A., Jones, C., Lenderlink, G., McDonald, A., McGrath, R., Navascues, B., Nielsen, N.W., Ødegaard, V., Rodriguez, E., Rummukainen, M., Rõõm, R., Sattler, K., Sass, B.H., Savijärvi, H., Schreur, B.W., Sigg, R., The, H. and Tijm, S., 2002. HIRLAM-5 scientific documentation. Swedish Meteorological and Hydrological Institute (SMHI) Norrköping, Sweden. 